\title{
Pulmonary function, exhaled nitric oxide and symptoms in asthma patients with obesity: a cross-sectional study
}

\author{
Marise J. Kasteleyn ${ }^{1}$, Tobias N. Bonten ${ }^{1 *}$, Renée de Mutsert ${ }^{3}$, Willemien Thijs ${ }^{1}$, Pieter S. Hiemstra' ${ }^{1}$ Saskia le Cessie ${ }^{3}$,
} Frits R. Rosendaal ${ }^{3}$, Niels H. Chavannes ${ }^{2}$ and Christian Taube ${ }^{1,4}$

\begin{abstract}
Background: Obesity is a risk factor for the development of asthma. In patients with obesity the diagnosis of asthma is often based on symptoms, but without objective measurements. Nevertheless, obesity-associated asthma is recognized as a distinct asthma phenotype. Therefore, this study explores lung function and symptoms in asthma patients with and without obesity.

Methods: The Netherlands Epidemiology of Obesity (NEO) study is a population-based cohort study with 6671 participants (aged 45-65 years) of whom 472 had asthma. Of this latter group, linear regression analysis was used to examine differences in lung function and symptoms between asthma patients with $(n=248)$ and without obesity $(n=224)$, and between asthma patients with and without increased Fe $\mathrm{NO}_{\mathrm{NO}}$. Analyses were adjusted for confounders.

Results: Asthma patients with obesity had lower predicted $\mathrm{FEV}_{1}$ and $\mathrm{FVC}$ values than patients without obesity [adjusted mean difference (MD) -3.3\% predicted, 95\% Cl -6.5, -0.2 ; adjusted MD $-5.0 \%$ predicted, $95 \% \mathrm{Cl}-7.8,-2.1$ ]. The prevalence of symptoms was higher in patients with obesity. Asthma patients with obesity and with increased $\mathrm{Fe}_{\mathrm{NO}}$ had lower $\mathrm{FEV}_{1}$ and $\mathrm{FEV}_{1} / \mathrm{FVC}$ values compared with those with low $\mathrm{Fe}_{\mathrm{NO}}$ (adjusted MD $-6.9 \%$ predicted, $95 \% \mathrm{Cl}$ $-11.7,-2.0 ;-2.4 \%, 95 \% \mathrm{Cl}-4.6,-0.2)$.

Conclusion: Asthma patients with obesity had lower FEV 1 and FVC values than patients without obesity. This suggests that patients with obesity have restrictive lung function changes, rather than obstructive changes. Asthma patients with obesity and increased $\mathrm{Fe}_{\mathrm{NO}}$ showed more obstructive changes. $\mathrm{Fe}_{\mathrm{NO}}$ might help to identify patients with eosinophilic inflammation-driven asthma, whereas patients with low $\mathrm{Fe}_{\mathrm{NO}}$ might have an obesity-associated asthma phenotype in which symptoms are partly caused by the obesity.
\end{abstract}

Keywords: Asthma, Obesity, Fe $\mathrm{NO}_{\mathrm{N}}$ Symptoms, Lung function

\section{Background}

Asthma and obesity are common conditions with an increasing prevalence. It is estimated that, in 2014, worldwide more than 600 million adults had obesity [1]. In the general population, the prevalence of asthma ranges from 1 to $8 \%$ [2]. Epidemiological studies have shown that obesity itself has a significant impact on respiratory function [3] and some studies

\footnotetext{
* Correspondence: t.n.bonten@lumc.nl

'Department of Pulmonology, Leiden University Medical Center, V6-22, PO Box 9600, 2300 RC Leiden, the Netherlands

Full list of author information is available at the end of the article
}

have suggested that obesity is also a risk factor to develop asthma [3-5]. Body mass index (BMI) has been shown to have little effect on spirometry results, while the expiratory reserve volume and functional residual capacity are reduced in people with obesity compared with people with normal weight [6]. Results regarding the relation between obesity and hyperresponsiveness are conflicting, with some indicating no relationship and others showing that BMI is associated with hyperresponsiveness [6].

Patients with and without obesity with a diagnosis of asthma differ in symptom severity, airway inflammation, 
age of asthma onset, sex, and treatment responsiveness. The Global Initiative for Asthma guidelines identify obesity-associated asthma as a distinct asthma phenotype $[2,7]$. Nevertheless, asthma patients with obesity also represent a heterogeneous patient group regarding airway inflammation, symptoms and asthma control [8]. Obesity-associated asthma does not necessarily involve the classical type $2 \mathrm{~T}$ helper (Th2)-driven inflammatory process; also, it is suggested that the group of asthma patients with obesity is composed of patients with a Th2 inflammation-driven asthma and other patients who are mainly symptomatic as a result of their increased body weight without evidence of Th2-driven airway inflammation [9]. Indeed, especially in patients with morbid obesity and a diagnosis of asthma, airway inflammation was not detected in bronchial biopsies [10]. The detection of airway inflammation is important, as patients with increased eosinophilic inflammation should be treated differently than patients without evidence of eosinophilic inflammation. Fractional exhaled nitric oxide $\left(\mathrm{Fe}_{\mathrm{NO}}\right)$ has a diagnostic accuracy similar to blood eosinophils in identifying sputum eosinophilia in adult asthma patients [11]. $\mathrm{Fe}_{\mathrm{NO}}$ measurement has emerged as a non-invasive, inexpensive and reliable test which is becoming available on a wider scale. Therefore, it may prove useful in the diagnosis and management of asthma in primary care, especially in patients with obesity. When evaluated at group level, $\mathrm{Fe}_{\mathrm{NO}}$ is lower in asthma patients with obesity than in asthma patients without obesity, [12] suggesting that the group of patients with apparent airway inflammation is lower in patients with obesity. However, asthma patients with overweight or obesity have worse asthma control and respond less to corticosteroid therapy than normal weight individuals with asthma [13]. Other strategies, such as weight loss, improve pulmonary function, asthma control and quality of life in asthma patients with obesity, suggesting that the increased body weight and the resulting mechanical impairment of the lung might be an important factor $[14,15]$.

It can be questioned whether patients with obesity and with symptoms of dyspnea are adequately diagnosed as asthma. According to current international guidelines, the diagnosis asthma is based on medical history, physical examination, lung function tests and additional tests [2]. However, objective methods to confirm the diagnosis asthma are not always used; [16] in 30\% of the adults with asthma, the diagnosis could not be confirmed by objective methods $[17,18]$. Van Huisstede et al. suggest that, in obesity, respiratory symptoms could be incorrectly ascribed to either the obesity or asthma, resulting in a substantial proportion of misdiagnosis in this group [19]. Whereas the study of van Huisstede et al. suggests a difference in misdiagnosis of asthma between patients with and without obesity, Aaron et al. showed that overdiagnosis was not more common in patients with obesity than in those without obesity [20]. In $32 \%$ of the asthma patients with obesity, the diagnosis could not be confirmed by objective tests, compared with $29 \%$ of the patients without obesity [20].

To provide more evidence on the role of obesity in asthma, this study examines i) differences in pulmonary function, $\mathrm{Fe}_{\mathrm{NO}}$ and symptoms between asthma patients with and without obesity, and ii) differences in lung function between asthma patients with and without increased $\mathrm{Fe}_{\mathrm{NO}}$. The emerging knowledge may help optimize treatment in patients with obesity experiencing respiratory symptoms.

\section{Methods}

\section{Study design and study population}

The Netherlands Epidemiology of Obesity (NEO) study is a population-based prospective cohort study including 6671 men and women (aged 45-65 years), with an oversampling of persons with a BMI of $\geq 27 \mathrm{~kg} / \mathrm{m}^{2}$. Details of the study design and data collection have been described previously [21]. Between September 2008 and September 2012 men and women aged 45-65 years, living in the greater area of Leiden (in the west of the Netherlands) and with a self-reported BMI of $\geq 27 \mathrm{~kg} / \mathrm{m}^{2}$ were invited to participate. In addition, all inhabitants aged 4565 years from one municipality (Leiderdorp) were also invited irrespective of their BMI.

Between 2012 and 2013 information on prescriptions and diagnoses was extracted from the electronic health records of the participants at their general practitioners. According to the guidelines of the Dutch College of General Practitioners, diagnoses are coded according to the International Classification of Primary Care (ICPC) [22]. In the patient records, the general practitioners link all contact moments to a care episode, which is coded with the ICPC. The information is listed under four categories: subjective, objective, evaluation and plan. Measurements are coded under the heading objective, ICPC codes under evaluation, and prescriptions under plan. Drug prescriptions in the electronic health records are coded according to the Anatomical Therapeutic Chemical (ATC) classification system [23].

The present study is a cross-sectional analysis of baseline measurements of all patients with an ICPCcoded diagnosis of asthma (R96) in their medical history $(n=513)$. Patients with missing values on the key outcomes were excluded $(n=41)$.

The Medical Ethical Committee of the Leiden University Medical Center (LUMC) approved the study protocol and all participants gave their written informed consent.

\section{Data collection in the NEO study}

Participants were invited to a baseline visit at the NEO study center of the LUMC after an overnight fast. Prior to the NEO study baseline visit, participants completed 
a questionnaire about demographics, lifestyle, clinical information and quality of life. Participants reported their highest level of education in 10 categories according to the Dutch educational system. We defined low education as no education, primary education or lower vocational training. Self-identified ethnicity of participants was reported in eight categories that we grouped into Caucasian and other. Smoking status was categorized in to current, former or never.

The questionnaire included several questions about pulmonary symptoms. Participants indicated which symptoms (dyspnea, wheezing, coughing including mucus, coughing without mucus) they had experienced during the last month. They were also asked to indicate whether those symptoms worsened during physical activity, contact with animals, house dust mite or pollen, foggy weather, or at night and/or getting up in the morning. Physical activity during leisure time was reported using the Short Questionnaire to Assess Health-enhancing physical activity questionnaire and expressed in metabolic equivalents of task (MET) hours per week (MET h/week) [24]. Participants were asked to bring all medication they had used in the month preceding the study visit to the NEO study site, i.e. both prescribed medication and self-medication. All medications they were using at that time were checked and recorded by the study nurse. At the NEO study center, several measurements were performed including a physical examination and blood sampling. BMI was calculated by dividing the weight in kilograms by the height in meters squared. The World Health Organization defines obesity as a BMI $\geq 30$ [1]. Duration of asthma was determined in two ways: i) as selfreported by the patient, and ii) calculated using the date of the first registration of the ICPC code asthma in the electronic health records. When using the registration date, the duration might be underestimated for patients with asthma since their youth, since electronic health records were introduced later. Therefore, in this study, we used the selfreported asthma duration; if this was missing, the date of the first registration of the ICPC code asthma was used.

\section{Pulmonary function tests}

All participants performed pulmonary function tests, including measurement of $\mathrm{Fe}_{\mathrm{NO}}$. These tests were performed at the Department of Pulmonology of the LUMC. Spirometry was performed according to the standards of the European Respiratory Society [25]. Testing was done in sitting position with nose clips in place. A spirometer (Jaeger Masterscreen PFT; Viasys Healthcare, Hoechberg, Germany) was used by trained technicians to measure forced expiratory volume in one second $\left(\mathrm{FEV}_{1}\right)$ and forced vital capacity (FVC). The $\mathrm{FEV}_{1}$ and $\mathrm{FVC}$ values with the highest sum of $\mathrm{FEV}_{1}$ and corresponding FVC value of three technically satisfactory and reproducible curves were registered for analysis. Curves were considered reproducible if the $\mathrm{FEV}_{1}$ and $\mathrm{FVC}$ values were within $5 \%$, and peak expiratory flow values within $10 \%$ of the highest values. When spirometric test results did not meet these criteria, but did include at least one technically acceptable curve, the values of this best performance were registered. $\mathrm{FEV}_{1} \%$ was defined as the $\mathrm{FEV}_{1}$ value expressed as a percentage of the predicted normal $\mathrm{FEV}_{1}$ and $\mathrm{FVC} \%$ as the $\mathrm{FVC}$ value expressed as a percentage of the predicted normal FVC, both predictions based on sex, age and height. The Tiffeneau index $\left(\mathrm{FEV}_{1} / \mathrm{FVC}\right)$ was calculated by dividing the registered $\mathrm{FEV}_{1}$ value by the registered $\mathrm{FVC}$ value.

\section{$\mathrm{Fe}_{\mathrm{NO}}$}

$\mathrm{Fe}_{\mathrm{NO}}$ was measured once using a portable analyzer, the NIOX MINO (Aerocrine AB, Solna, Sweden). We have previously shown that a single measurement suffices for the assessment of $\mathrm{Fe}_{\mathrm{NO}}$ in persons with overweight or obesity [26]. In the present study, a cut-off of $\mathrm{Fe}_{\mathrm{NO}}$ of $<25$ was used; this is a clinically relevant threshold for low $\mathrm{Fe}_{\mathrm{NO}}$ according to the American Thoracic Society [27].

\section{Statistical analysis}

Categorical variables were reported as numbers and percentages, normally distributed continuous variables as means with standard deviations (SD) and non-normally distributed continuous variables as medians with interquartile ranges (IQR), stratified by BMI $\left(<30 \mathrm{~kg} / \mathrm{m}^{2}\right.$ and $\left.\geq 30 \mathrm{~kg} / \mathrm{m}^{2}\right)$. Differences in baseline characteristics between participants with obesity (BMI $\geq 30 \mathrm{~kg} / \mathrm{m}^{2}$ and without obesity $\left(\mathrm{BMI}<30 \mathrm{~kg} / \mathrm{m}^{2}\right)$ were tested, using linear regression analyses, separately for participants with and without an ICPC-coded asthma. For nonnormally distributed variables and dichotomous variables, linear regression analyses with robust standard errors were used.

Interaction effects between the main independent variables (asthma and obesity, and obesity and $\mathrm{Fe}_{\mathrm{NO}}$ ) were tested using linear regression analyses. For non-normally distributed variables and dichotomous variables linear regression analyses with robust standard errors were used. Interaction effects between obesity and asthma were tested in the total population with regard to lung function and $\mathrm{Fe}_{\mathrm{NO}}$, and the symptoms were also tested. Furthermore, interaction effects between obesity and $\mathrm{Fe}_{\mathrm{NO}}$ were tested in the asthma population. For the outcomes for which a significant interaction was found, the main effects were analyzed in the different subgroups.

Irrespective of the results of the interaction analyses, the asthma population was explored in more detail. In participants with asthma, differences in pulmonary function, $\mathrm{Fe}_{\mathrm{NO}}$, symptoms and use of inhalation corticosteroids (ICS) between those with and without obesity were examined using linear regression analyses. In addition, differences in pulmonary function, symptoms 
and ICS use were examined between asthma patients with and without increased $\mathrm{Fe}_{\mathrm{NO}}$ separately for those with and without obesity. In the case that the outcome was binary, robust standard errors were used to estimate risk difference. Adjustment for confounders was based on literature. Analyses were adjusted for age, sex, smoking, education levels, ethnicity, physical activity, alcohol use, and prescription of ICS. (Analyses for ICS use were not adjusted for prescription of ICS). These variables might act as confounders since they are associated with one of the main outcomes (obesity and/or $\mathrm{Fe}_{\mathrm{NO}}$ ) and with one or more of the outcomes.

Analyses were performed with STATA Statistical Software (Statacorp, College Station, Texas, USA), version 12.0.

\section{Results}

Of the 6671 participants, 637 were excluded due to missing values. Of the 6034 complete cases, 472 had an ICPC-coded diagnosis of asthma in their electronic health records (Fig. 1).

Baseline characteristics of the 472 included asthma patients (grouped according to $\mathrm{BMI}<$ and $\geq 30$ ) are presented in Table 1 . Of these 472 patients, 248 (52\%) had a $\mathrm{BMI} \geq 30 \mathrm{~kg} / \mathrm{m}^{2}$. Most asthma patients were women $(n=287,61 \%)$, the mean (SD) age was 55.1 (6.1) years and the mean (SD) BMI was 31.2 (5.3). The asthma patients with obesity had a significantly lower education, were less physically active, had a lower alcohol intake, and a higher BMI (Table 1). Baseline characteristics of the participants without asthma (grouped according to $\mathrm{BMI}<$ and $\geq 30$ ) are presented in Additional file 1: Table S1.

In the total population, significant interaction effects between obesity and asthma were found for wheezing, worsening of symptoms during exercise, and worsening of symptoms during getting up in the morning. Differences in wheezing, worsening of symptoms during exercise and worsening of symptoms during getting up in the morning were more pronounced in participants with asthma compared with participants without asthma (Table 2). In the total population, no significant interaction effects between obesity and asthma were found for $\mathrm{FEV}_{1} \%$ predicted, FVC \% predicted, $\mathrm{FEV}_{1} / \mathrm{FVC}, \mathrm{Fe}_{\mathrm{NO}}$, dyspnea, coughing with mucus, coughing without mucus and worsening of symptoms during dust/pollen/animal exposure, during foggy weather or at night. In the asthma population, no significant interactions were found between obesity and $\mathrm{Fe}_{\mathrm{NO}}$.

Differences in lung function and symptoms between asthma patients with and without obesity are reported in Table 3. Regarding lung function, asthma patients with obesity had lower predicted $\mathrm{FEV}_{1}$ and $\mathrm{FVC}$ values than patients without obesity. The prevalence of the symptoms dyspnea and wheezing was higher in patients with obesity than in those without obesity, and symptoms more often worsened during physical activity in the group with obesity than in those without obesity.

Of the asthma patients without obesity, 57 (25.4\%) had $\mathrm{Fe}_{\mathrm{NO}}$ levels of $\geq 25 \mathrm{ppb}$, whereas 167 (74.6\%) had $\mathrm{Fe}_{\mathrm{NO}}$ levels $<25 \mathrm{ppb}$ (Fig. 1). No differences in lung function, symptoms and ICS use were found between asthma patients without obesity, with and without increased $\mathrm{Fe}_{\mathrm{NO}}$ (Table 4).

The majority of asthma patients with obesity had a $\mathrm{Fe}_{\mathrm{NO}}$ value $<25 \mathrm{ppb}$ (Fig. 1). Differences between patients with and without increased $\mathrm{Fe}_{\mathrm{NO}}$ are presented in Table 5. Patients with low $\mathrm{Fe}_{\mathrm{NO}}$ levels had better $\mathrm{FEV}_{1}$ values and $\mathrm{FEV}_{1} / \mathrm{FVC}$ values than patients with increased $\mathrm{Fe}_{\mathrm{NO}}$. In patients with higher $\mathrm{Fe}_{\mathrm{NO}}$ levels, symptoms more often worsened during exposure to dust, pollen or animals compared with patients with lower $\mathrm{Fe}_{\mathrm{NO}}$.

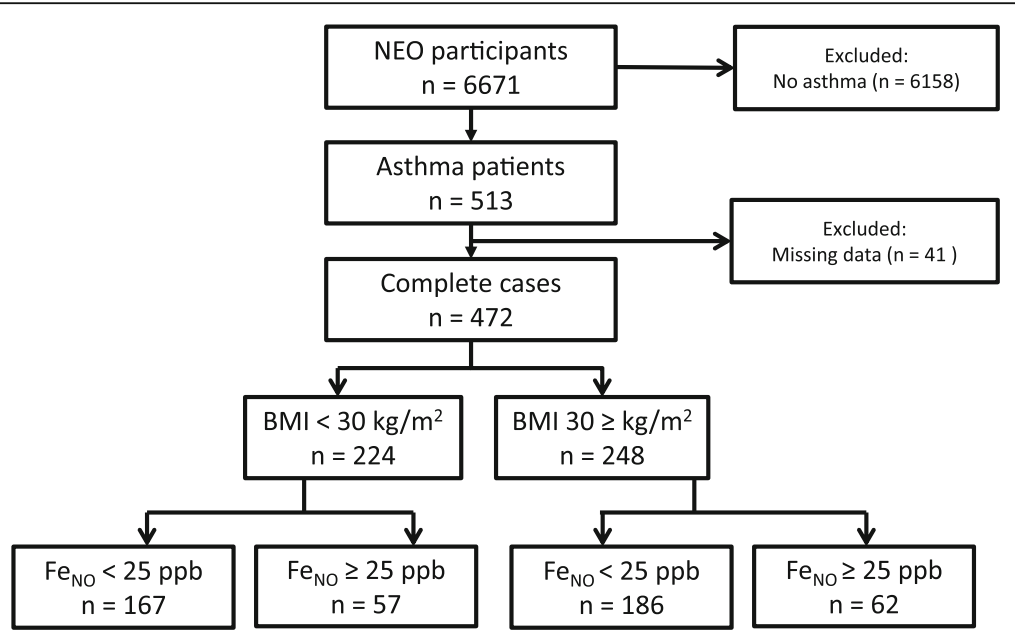

Fig. 1 Flowchart. Fe $\mathrm{NO}_{\mathrm{NO}}$ : fractional exhaled nitric oxide; ppb: parts per billion 
Table 1 Baseline characteristics of asthma patients from the Netherlands Epidemiology of Obesity study $(n=472)$

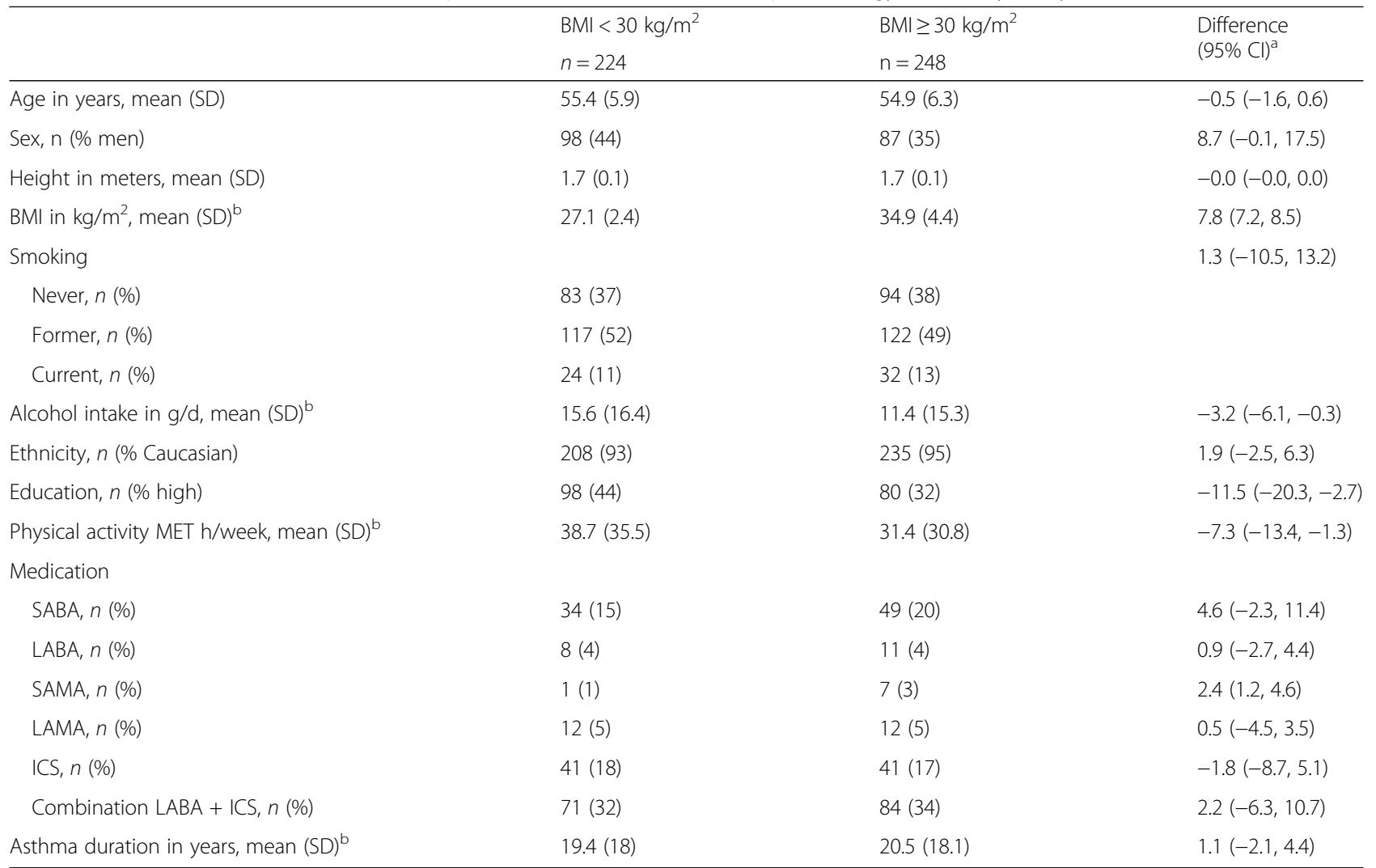

$B M I$ body mass index, $g / d$ gram/day, MET metabolic equivalent of tasks, SABA short-acting beta-agonists, LABA long-acting beta-agonists, SAMA short-acting muscarinic antagonists, LAMA long-acting $\beta 2$-adrenergic antagonists, ICS inhalation corticosteroids

${ }^{a}$ Differences are presented as difference in means for continuous variables and difference in percentage for categorical variables

${ }^{b}$ Linear regression analyses with robust standard errors are used for dichotomous variables and non-normally distributed variables

\section{Discussion}

The aim of this study was to examine differences in pulmonary function, $\mathrm{Fe}_{\mathrm{NO}}$ and symptoms between asthma patients with and without obesity, and to describe differences in lung function and symptoms between asthma patients with and without increased $\mathrm{Fe}_{\mathrm{NO}}$. The results of this study suggest that: 1) differences between individuals with and without obesity in wheezing, worsening of symptoms during physical activity and worsening of symptoms during getting up in the morning are more pronounced in asthma patients compared with those without asthma, 2) patients with obesity and the diagnosis of asthma have decreased $\mathrm{FEV}_{1}$ and FVC values compared with asthma patients without obesity, 3) patients with obesity report more respiratory symptoms than asthma patients without obesity, and 4) asthma patients with obesity and with increased $\mathrm{Fe}_{\mathrm{NO}}$ have lower $\mathrm{FEV}_{1}$ and $\mathrm{FEV}_{1} / \mathrm{FVC}$ values, and more symptoms due to environmental triggers, than patients with low FeNO levels.

In previous studies (and in our study), the use of spirometry to evaluate lung function in persons with morbid obesity revealed a proportional reduction in FVC and

Table 2 Main effects of significant interactions between asthma and obesity in the total population

\begin{tabular}{|c|c|c|c|c|c|c|c|c|}
\hline & \multicolumn{4}{|c|}{ Participants without asthma } & \multicolumn{4}{|c|}{ Participants with asthma } \\
\hline & \multicolumn{4}{|l|}{$n=5562$} & \multicolumn{4}{|l|}{$N=472$} \\
\hline & $\begin{array}{l}\mathrm{BMl}<30 \mathrm{~kg} / \mathrm{m}^{2} \\
n=3099\end{array}$ & $\begin{array}{l}\mathrm{BMI} \geq 30 \mathrm{~kg} / \mathrm{m}^{2} \\
n=2463\end{array}$ & $\begin{array}{l}\text { Unadjusted } \\
\text { difference } \\
(95 \% \mathrm{Cl})^{\mathrm{a}}\end{array}$ & $\begin{array}{l}\text { Adjusted } \\
\text { difference } \\
(95 \% \mathrm{Cl})^{\mathrm{a}}\end{array}$ & $\begin{array}{l}\mathrm{BMI}<30 \mathrm{~kg} / \mathrm{m}^{2} \\
n=224\end{array}$ & $\begin{array}{l}\mathrm{BMI} \geq 30 \mathrm{~kg} / \mathrm{m}^{2} \\
n=248\end{array}$ & $\begin{array}{l}\text { Unadjusted } \\
\text { difference } \\
(95 \% \mathrm{Cl})^{a}\end{array}$ & $\begin{array}{l}\text { Adjusted } \\
\text { difference } \\
(95 \% \mathrm{Cl})\end{array}$ \\
\hline Wheezing, $n(\%)$ & $120(4)$ & $192(8)$ & $3.9(2.7,5.1)$ & $3.1(1.9,4.3)$ & $39(17)$ & $88(35)$ & $18.1(10.3,25.9)$ & $18.6(10.8,26.3)$ \\
\hline Exercise, $n(\%)$ & $259(8)$ & $324(13)$ & $4.8(3.1,6.5)$ & $3.6(1.9,5.2)$ & $77(34)$ & $122(49)$ & $14.8(6.0,2.4)$ & $13.0(4.2,21.6)$ \\
\hline Morning, $n(\%)$ & $173(6)$ & $140(6)$ & $0.1(-1.1,1.3)$ & $0.2(-1.4,1.1)$ & $33(15)$ & $17(7)$ & $-7.9(-13.5,-2.2)$ & $-8.1(-14.0,-2.2)$ \\
\hline
\end{tabular}


Table 3 Pulmonary function, Fe $\mathrm{e}_{\mathrm{NO}}$ and symptoms in asthma patients with and without obesity $(n=472)$

\begin{tabular}{|c|c|c|c|c|}
\hline & $\mathrm{BMI}<30 \mathrm{~kg} / \mathrm{m}^{2} n=224$ & $\begin{array}{l}\mathrm{BMI} \geq 30 \mathrm{~kg} / \mathrm{m}^{2} \\
n=248\end{array}$ & $\begin{array}{l}\text { Unadjusted } \\
\text { difference } \\
(95 \% \text { Cl) }\end{array}$ & $\begin{array}{l}\text { Adjusted } \\
\text { difference } \\
(95 \% \mathrm{Cl})^{\mathrm{a}}\end{array}$ \\
\hline \multicolumn{5}{|l|}{ Lung function } \\
\hline $\mathrm{FEV}_{1}, \%$ pred, mean (SD) & $99.9(18.1)$ & $97.0(17.1)$ & $-2.9(-6.1,0.3)$ & $-3.2(-6.3,-0.03)$ \\
\hline FVC, \% pred, mean (SD) & $111.8(17.9)$ & $107.4(15.5)$ & $-4.4(-7.4,-1.4)$ & $-4.9(-7.8,-2.0)$ \\
\hline $\mathrm{FEV}_{1} / \mathrm{FVC}$, mean (SD) & $74.0(8.1)$ & $74.9(8.0)$ & $0.9(-0.5,2.4)$ & $0.5(-0.9,1.9)$ \\
\hline $\mathrm{Fe}_{\mathrm{NO}}, \mathrm{ppb}$, mean (SD) & $21.9(16.9)$ & $19.2(13.9)$ & $-2.7(-5.5,0.1)$ & $-1.8(-4.6,1.0)$ \\
\hline \multicolumn{5}{|l|}{ Symptoms } \\
\hline Dyspnea, $n(\%)$ & $78(35)$ & $114(46)$ & $11.1(2.3,20.0)$ & $9.5(0.8,18.2)$ \\
\hline Wheezing, $n(\%)$ & $39(17)$ & $88(36)$ & $18.1(10.3,25.9)$ & $18.5(10.8,26.2)$ \\
\hline Coughing with mucus, $n$ (\%) & $49(22)$ & $56(23)$ & $0.7(-6.8,8.3)$ & $0.9(-6.5,8.4)$ \\
\hline Coughing without mucus, $n$ (\%) & $72(32)$ & $78(32)$ & $-0.7(-9.1,7.8)$ & $-2.0(-10.4,6.3)$ \\
\hline \multicolumn{5}{|l|}{ Symptoms worsen during: } \\
\hline Physical activity, n (\%) & $77(34)$ & $121(49)$ & $14.8(6.0,23.7)$ & $12.9(4.2,21.6)$ \\
\hline Dust/pollen/animal exposure, $n$ (\%) & $79(35)$ & $75(30)$ & $-5.0(-13.5,3.5)$ & $-3.5(-11.6,4.5)$ \\
\hline Foggy weather, $n(\%)$ & $78(35)$ & $94(38)$ & $3.1(-5.6,11.8)$ & $1.7(-6.6,9.9)$ \\
\hline Night, $n(\%)$ & $26(12)$ & $38(15)$ & $3.7(-2.5,9.9)$ & $3.0(-3.3,9.3)$ \\
\hline Getting up in the morning, $n(\%)$ & $33(15)$ & $17(7)$ & $-7.9(-13.5,-2.2)$ & $-8.1(-14.0,-2.2)$ \\
\hline ICS prescription, $n(\%)$ & $107(48)$ & $123(50)$ & $1.8(-7.2,10.9)$ & $2.5(-6.7,11.7)$ \\
\hline
\end{tabular}

$B M I$ body mass index, $C l$ confidence interval, $F E V_{1}$ forced expiratory volume in one second, $F V C$ forced vital capacity, $F e_{N O}$ fractional exhaled nitric oxide, $p p b$ parts per billion, ICS inhalation corticosteroids

${ }^{a}$ Differences are presented as difference in means for continuous variables and difference in percentage for categorical variables

Analyses are adjusted for age, sex, smoking, education levels, ethnicity, physical activity, alcohol use, and prescription of ICS

Table 4 Asthma patients without obesity: differences in pulmonary function between patients with and without increased Fe $e_{N O}$ $(n=224)$

$\begin{array}{llll}\mathrm{Fe}_{\mathrm{NO}}<25 \mathrm{ppb} n=167 & \mathrm{Fe}_{\mathrm{NO}} \geq 25 \mathrm{ppb} n=57 & \begin{array}{l}\text { Unadjusted } \\ \text { difference } \\ (95 \% \mathrm{Cl})^{\mathrm{a}}\end{array} & \begin{array}{l}\text { Adjusted } \\ \text { difference } \\ (95 \% \mathrm{Cl})^{\mathrm{a}}\end{array}\end{array}$

\begin{tabular}{|c|c|c|c|c|}
\hline \multicolumn{5}{|l|}{ Lung function } \\
\hline $\mathrm{FEV}_{1}, \%$ pred, mean (SD) & $101.5(17.7)$ & $95.2(18.7)$ & $-6.4(-11.8,-0.9)$ & $-4.4(-9.7,0.9)$ \\
\hline FVC, \% pred, mean (SD) & $112.9(17.9)$ & $108.5(18.5)$ & $-4.4(-9.7,1.0)$ & $-1.6(-6.6,3.4)$ \\
\hline $\mathrm{FEV}_{1} / \mathrm{FVC}$, mean (SD) & $74.5(8.0)$ & $72.2(8.4)$ & $-2.3(-4.8,0.1)$ & $-1.9(-4.4,0.6)$ \\
\hline \multicolumn{5}{|l|}{ Symptoms } \\
\hline Dyspnea, $n(\%)$ & $60(36)$ & $18(32)$ & $-4.3(-18.6,9.9)$ & $-1.1(-15.4,13.3)$ \\
\hline Wheezing, $n(\%)$ & $31(19)$ & $8(14)$ & $-4.5(-15.4,6.4)$ & $-6.4(-17.5,4.8)$ \\
\hline Coughing with mucus, $n$ (\%) & $41(26)$ & $8(14)$ & $-10.5(-21.8,0.7)$ & $-10.5(-21.9,1.0)$ \\
\hline Coughing without mucus, $n$ (\%) & $58(35)$ & $14(26)$ & $-10.2(-23.6,3.3)$ & $-12.2(-24.5,0.1)$ \\
\hline \multicolumn{5}{|l|}{ Symptoms worsen during: } \\
\hline Physical activity, $n$ (\%) & $62(37)$ & $15(26)$ & $-10.8(-24.5,2.9)$ & $-11.1(-24.2,2.1)$ \\
\hline Dust/pollen/animal exposure, $n(\%)$ & $58(35)$ & $21(37)$ & $2.1(-12.5,16.7)$ & $5.5(-8.8,19.8)$ \\
\hline Foggy weather, $n(\%)$ & $61(37)$ & $17(30)$ & $-6.7(-20.8,7.4)$ & $-2.4(-15.6,10.7)$ \\
\hline Night, $n(\%)$ & $17(10)$ & $9(16)$ & $5.6(-5.0,16.2)$ & $4.4(-6.5,15.3)$ \\
\hline Getting up in the morning, $n(\%)$ & $24(14)$ & $9(16)$ & $1.4(-9.5,12.4)$ & $0.7(-9.9,11.4)$ \\
\hline ICS prescription, $n(\%)$ & $83(50)$ & $24(42)$ & $-7.6(-22.7,7.5)$ & $-8.6(-24.0,6.7)$ \\
\hline
\end{tabular}

$\mathrm{Fe}_{\mathrm{NO}}$ fractional exhaled nitric oxide, $\mathrm{Cl}$ confidence interval, $F E V_{1}$ forced expiratory volume in one second, $F V C$ forced vital capacity, ppb parts per billion, ICS inhalation corticosteroids

${ }^{a}$ Differences are presented as difference in means for continuous variables and difference in percentage for categorical variables

Analyses are adjusted for age, sex, smoking, education levels, ethnicity, physical activity, alcohol use, and prescription of ICS 
Table 5 Asthma patients with obesity: differences in pulmonary function between patients with and without increased Fe $\mathrm{NO}_{\mathrm{N}}$ $(n=248)$

\begin{tabular}{|c|c|c|c|c|}
\hline & $\mathrm{Fe}_{\mathrm{NO}}<25 \mathrm{ppb} n=186$ & $\mathrm{Fe}_{\mathrm{NO}} \geq 25 \mathrm{ppb} n=62$ & $\begin{array}{l}\text { Unadjusted difference } \\
(95 \% \mathrm{Cl})^{\mathrm{a}}\end{array}$ & $\begin{array}{l}\text { Adjusted difference } \\
(95 \% \mathrm{Cl})^{\mathrm{a}}\end{array}$ \\
\hline \multicolumn{5}{|l|}{ Lung function } \\
\hline $\mathrm{FEV}_{1}, \%$ pred, mean (SD) & $99.0(16.5)$ & $91.2(17.8)$ & $-7.8(-12.6,-2.9)$ & $-6.9(-11.9,-2.0)$ \\
\hline FVC, \% pred, mean (SD) & $108.6(15.2)$ & $103.6(16.0)$ & $-5.0(-9.4,-0.6)$ & $-4.0(-8.3,0.4)$ \\
\hline $\mathrm{FEV}_{1} / \mathrm{FVC}$, mean (SD) & $75.7(7.6)$ & $72.4(8.7)$ & $-3.3(-5.6,-1.0)$ & $-2.5(-4.7,-0.2)$ \\
\hline \multicolumn{5}{|l|}{ Symptoms } \\
\hline Dyspnoea, $n(\%)$ & $84(45)$ & $30(48)$ & $3.2(-11.3,17,7)$ & $6.0(-8.5,20.5)$ \\
\hline Wheezing, $n$ (\%) & $66(36)$ & $22(36)$ & $-0.0(-13.9,13.9)$ & $0.6(-13.5,14.7)$ \\
\hline Coughing with mucus, $n$ (\%) & $47(25)$ & $9(15)$ & $-10.8(-21.6,0.1)$ & $-11.3(-22.2,-0.4)$ \\
\hline Coughing without mucus, $n(\%)$ & $61(33)$ & $17(27)$ & $-5.4(-18.5,7.7)$ & $-4.8(-17.5,8.0)$ \\
\hline \multicolumn{5}{|l|}{ Symptoms worsen during: } \\
\hline Physical activity, $n(\%)$ & $95(51)$ & $27(44)$ & $-7.5(-21.9,6.9)$ & $-4.5(-18.9,10.0)$ \\
\hline Dust/pollen/animal exposure, $n$ (\%) & $48(26)$ & $27(44)$ & $17.7(3.8,31.7)$ & $16.2(3.5,28.8)$ \\
\hline Foggy weather, $n(\%)$ & $68(37)$ & $26(42)$ & $5.4(-8.8,19.6)$ & $9.0(-4.4,22.3)$ \\
\hline Night, $n(\%)$ & $27(15)$ & $11(18)$ & $3.2(-7.6,14.1)$ & $4.3(-6.7,15.2)$ \\
\hline Getting up in the morning, $n(\%)$ & $13(7)$ & $4(7)$ & $0.5(-7.7,6.7)$ & $-1.2(-8.7,6.2)$ \\
\hline ICS prescription, $n(\%)$ & $93(50)$ & $30(48)$ & $-1.6(-16.1,12.9)$ & $0.2(-14.7,15.1)$ \\
\hline
\end{tabular}

$\mathrm{Fe}_{\mathrm{NO}}$ fractional exhaled nitric oxide, $\mathrm{Cl}$ confidence interval, $F E V$, forced expiratory volume in one second, FVC forced vital capacity, $p p b$ parts per billion, ICS inhalation corticosteroids

${ }^{a}$ Differences are presented as difference in means for continuous variables and difference in percentage for categorical variables

Analyses are adjusted for age, sex, smoking, education levels, ethnicity, physical activity, alcohol use, and prescription of ICS

$\mathrm{FEV}_{1}$, suggesting the occurrence of restrictive lung function impairment [28]. The $\mathrm{FEV}_{1} / \mathrm{FVC}$ ratio is generally well preserved or elevated, even in individuals with morbid obesity, indicating that $\mathrm{FEV}_{1}$ and $\mathrm{FVC}$ are affected at the same rate [29]. Also in the present study, the $\mathrm{FEV}_{1} /$ FVC ratio was not impaired in patients with obesity, suggesting no evidence for increased airway obstruction compared with patients without obesity.

In the present study, no difference was found in $\mathrm{Fe}_{\mathrm{NO}}$ levels between asthma patients with and without obesity. This is in contrast with the studies of Komakula et al. [30] and Barros et al. [31] who reported a negative association between $\mathrm{BMI}$ and $\mathrm{Fe}_{\mathrm{NO}}$ in asthma patients. Komakula et al. suggested that BMI may increase airway oxidative stress in asthmatics; this impact of oxidative stress on $\mathrm{NO}$ levels might explain the reported negative association [30]. Because we did not measure oxidative stress in the NEO study, we were unable to check its association with BMI in the present population.

In our study, patients with obesity reported more respiratory symptoms than asthma patients without obesity. Similarly, previous studies showed that individuals with overweight and obesity are more likely to have symptoms of wheezing and dyspnea than individuals with a normal BMI, even in the absence of demonstrable lung disease [32]. The origin of these symptoms is suggested to lie mainly with the overweight and not with airway obstruction $[33,34]$. Because dyspnea can be attributed to either asthma or obesity, people with obesity are often misdiagnosed with asthma [19, 34]. Carpio et al. showed that a misdiagnosis of asthma in individuals with obesity could be attributed to an increased perception of dyspnea which, during exercise, is mainly associated with systemic inflammation and excessive ventilation for metabolic demands [35]. Their results confirm the suggestion that the main difference between subjects with obesity with misdiagnosed asthma and control subjects with obesity lies in a higher perception of dyspnea during the bronchial challenge and exercise, to such an extent that it is similar to that of asthmatic subjects.

Patients without obesity more frequently reported worsening of symptoms during getting up in the morning than patients with obesity. Because asthma symptoms fluctuate during the day and the presence of morning symptoms is common in asthma [36], one would expect such a worsening of symptoms in the morning in an asthma population. Therefore, it is remarkable that this was reported much more frequently by the asthma patients without obesity than by those with obesity, and that this difference was not found in the patients without asthma. This is an indication that asthma patients with obesity represent a specific group of asthma patients, in which symptoms are at least partly due to the overweight. 
In patients both with and without obesity, the number of patients with increased $\mathrm{Fe}_{\mathrm{NO}}$ levels was around $25 \%$. Because increased $\mathrm{Fe}_{\mathrm{NO}}$ values predict eosinophilic airway inflammation in both groups [11], we additionally stratified the analyses by high and low $\mathrm{Fe}_{\mathrm{NO}}$ values. It can be speculated that increased $\mathrm{Fe}_{\mathrm{NO}}$ reflects Th2driven airway inflammation whereas patients with a low $\mathrm{Fe}_{\mathrm{NO}}$ represent a phenotype in which symptoms are caused by their obesity rather than by airway inflammation and airway obstruction. However, it can also be argued that the difference between the two groups is due to the fact that patients in the low $\mathrm{Fe}_{\mathrm{NO}}$ group were well controlled and adequately treated whereas patients in the high $\mathrm{Fe}_{\mathrm{NO}}$ group were poorly controlled. Nevertheless, symptoms like dyspnea, wheezing and cough were present in similar numbers in asthma patients with increased or normal $\mathrm{Fe}_{\mathrm{NO}}$ levels, suggesting that the disease control was similar in both groups. We observed that both obese and non-obese asthma patients with low $\mathrm{Fe}_{\mathrm{NO}}$ levels more often reported cough with mucus than those with high FeNO. This is unexpected, also in view of a recent metaanalysis showing that high $\mathrm{Fe}_{\mathrm{NO}}$ can be used to identify patients with cough-variant asthma in adult patients with chronic cough [37]. Our observations suggest that, within this asthma population, coughing with mucus is associated with a non-eosinophilic phenotype. Furthermore, coughing without mucus is relatively common in primary care, which might influence the results. In the group of asthma patients without obesity, there were no differences in lung function or symptoms between patients with high and low $\mathrm{Fe}_{\mathrm{NO}}$. Interestingly, asthma patients with obesity and with increased $\mathrm{Fe}_{\mathrm{NO}}$ had lower $\mathrm{FEV}_{1}$ values and $\mathrm{FEV}_{1} / \mathrm{FVC}$ compared with patients with lower $\mathrm{Fe}_{\mathrm{NO}}$ levels, suggesting increased airway obstruction in this group. In addition, in patients with obesity and with increased $\mathrm{Fe}_{\mathrm{NO}}$, symptoms more often worsened on exposure to pollen, dust or animals, suggesting the presence of an allergic component in this group. Therefore, the present study suggests that $\mathrm{Fe}_{\mathrm{NO}}$ can be helpful to distinguish between Th2-driven asthma and obesity-associated dyspnea symptoms. Since the specificity of $\mathrm{Fe}_{\mathrm{NO}}$ in the diagnosis of asthma is higher than the sensitivity, there is a higher potential for ruling in than for ruling out the diagnosis of asthma [38]. Nevertheless, in the absence of information about hyperreponsiveness, the question remains as to whether or not those individuals with the obesity-associated phenotype do in fact have asthma.

Obtaining a correct diagnosis of asthma in patients with obesity is important because, in the obesity-associated asthma group, other treatments (e.g. weight loss strategies) might be more efficient than pharmacological treatment. Indeed, weight loss in asthma patients with obesity can improve asthma control, asthma severity, lung function and quality of life, $[14,15]$ whereas it is refractory to standard asthma medications, including oral corticosteroids [39]. Nevertheless, in this population-based cohort, we observed that $50 \%$ of the asthma patients with obesity and with low $\mathrm{Fe}_{\mathrm{NO}}$ levels were treated with ICS.

In addition to $\mathrm{Fe}_{\mathrm{NO}}$, airway hyperresponsiveness assessed by methacholine challenge might also be used to differentiate between obesity-induced symptoms and symptoms due to asthma. Obesity, by itself, is not sufficient to alter airway responsiveness to methacholine in non-asthmatic subjects with normal airway responsiveness, although they do experience more dyspnea [40]. On the one hand, the use of $\mathrm{Fe}_{\mathrm{NO}}$ could be preferred for the diagnosis of asthma patients with obesity, since this is less invasive than methacholine challenge testing. However, we cannot rule out that there is a group with hyperresponsiveness and without increased $\mathrm{Fe}_{\mathrm{NO}}$ who might benefit from weight loss [15].

A strength of this study is that a large group of asthma patients (with an oversampling of individuals with overweight) were examined in detail, including information on pulmonary function, symptoms, FeNO levels and medication prescription. Also, for these patients ICPCcoded asthma was used, whereas most other studies rely on self-reported asthma.

A limitation of the study is that we have no information on several variables that can be used for the diagnosis of asthma, including reversibility testing, methacholine provocation testing, and blood or sputum eosinophils or immunoglobulin E. However, $\mathrm{Fe}_{\mathrm{NO}}$ has a diagnostic accuracy comparable to blood eosinophils in identifying sputum eosinophilia in adult asthma patients, irrespective of the asthma phenotype such as severe, non-atopic, obese and smoking-related asthma [11]. Furthermore, because both pulmonary function and $\mathrm{Fe}_{\mathrm{NO}}$ vary over time as a result of treatment, participants might have low $\mathrm{Fe}_{\mathrm{NO}}$ levels during the study visit whereas at other moments their $\mathrm{Fe}_{\mathrm{NO}}$ levels might be increased. Also, although both smoking and ICS can influence $\mathrm{Fe}_{\mathrm{NO}}$ levels, all our analyses were adjusted for these potential confounders. Another limitation is the oversampling of people with a $B M I \geq 27 \mathrm{~kg} / \mathrm{m}^{2}$, which might hamper generalizability of the results to lean people. Nevertheless, in the present study, because the differences found between high BMI and low BMI are probably conservative, differences between the groups will likely be even more pronounced when considering normal weight versus obesity.

Future studies should focus on the effectiveness of using $\mathrm{Fe}_{\mathrm{NO}}$ in the diagnosis of asthma in individuals with obesity, where high $\mathrm{Fe}_{\mathrm{NO}}$ levels suggest Th2-driven asthma that should be treated with ICS, and low $\mathrm{Fe}_{\mathrm{NO}}$ levels indicate obesity-associated symptoms for which intentional weight loss might be more effective. Also, the long-term effect of weight loss on asthma severity 
and control should be further investigated, since few studies have focused on long-term effects [41]. Alternative treatments should also be investigated, since early-onset obesity-associated asthma responds poorly to weight loss [42]. Finally, because obesity affects the respiratory system via changes in physiological mechanisms due to fat deposition in the chest wall, abdomen and upper airways (leading to symptoms of dyspnea), but also via systemic inflammation, more evidence on the association between mechanical and systemic processes and lung function is needed for a better understanding of the relationship between obesity and asthma.

\section{Conclusions}

In conclusion, this study shows that these patients with obesity and the diagnosis of asthma have worse lung function and more symptoms compared with asthma patients without obesity. This suggests that patients with obesity have restrictive lung function changes, rather than obstructive changes. In addition, asthma patients with obesity and increased $\mathrm{Fe}_{\mathrm{NO}}$ had lower $\mathrm{FEV}_{1}$ and $\mathrm{FEV}_{1} / \mathrm{FVC}$ values, and more symptoms due to environmental triggers, than patients with low FeNO levels. $\mathrm{Fe}_{\mathrm{NO}}$ might help to differentiate between an asthma phenotype, where high $\mathrm{Fe}_{\mathrm{NO}}$ identifies patients with eosinophilic inflammation-driven asthma and patients with low $\mathrm{Fe}_{\mathrm{NO}}$ might have an obesity-associated asthma phenotype, in which symptoms are partly caused by the obesity. This knowledge might help to optimize treatment in patients with obesity who experience respiratory symptoms.

\section{Additional file}

Additional file 1: Table S1. Baseline characteristics of participants without asthma from the Netherlands Epidemiology of Obesity study $(n=5562)$. (DOCX $12 \mathrm{~kb})$

\section{Abbreviations}

ATC: Anatomical therapeutic chemical; Fe $\mathrm{NO}_{\mathrm{NO}}$ : Fractional exhaled nitric oxide; ICPC: International classification of primary care; ICS: Inhalation corticosteroids; LABA: Long-acting beta-agonists; LAMA: Long-acting $\beta 2-$ adrenergic antagonists; LUMC: Leiden University Medical Center; MET: Metabolic equivalents of task; NEO: Netherlands Epidemiology of Obesity; Ppb: Parts per billion; SABA: Short-acting beta-agonists; SAMA: Short-acting muscarinic antagonists; Th2: type $2 \mathrm{~T}$ helper

\section{Acknowledgments}

The authors thank all individuals who participated in the Netherlands Epidemiology Obesity (NEO) study. We also thank all participating general practitioners for inviting eligible patients, all research nurses for collecting the data, and I. de Jonge, MSc for management of the NEO study data.

\section{Funding}

The NEO study is supported by the participating Departments, the Division and the Board of Directors of the Leiden University Medical Center, and by the Leiden University, Research Profile Area 'Vascular and Regenerative Medicine'.

Dr. Kasteleyn was supported with an unrestricted research grant from Chiesi.

\section{Availability of data and materials}

Since we are working on a follow-up manuscript using the same data, we do not wish to share the data at this moment.

\section{Authors' contributions}

MJK and TNB were involved in study concept, data analysis and interpretation, and drafting of the manuscript. RM was involved in the NEO concept and design, and contributed to the data analysis, interpretation of the data and manuscript revision. WT and PSH contributed to the interpretation of the data and manuscript revision. SC was involved in the NEO concept and design, supported the statistical analyses and contributed to the interpretation of the data and manuscript revision. FRR was involved in the NEO concept and design, contributed to the interpretation of the data and manuscript revision. $\mathrm{NHC}$ and $\mathrm{CT}$ were involved in study concept and contributed to interpretation of the data and manuscript revision. All authors read and approved the final manuscript.

\section{Ethics approval and consent to participate}

The Medical Ethical Committee of the Leiden University Medical Center (LUMC) approved the study protocol and all participants provided written informed consent.

\section{Consent for publication}

Not applicable.

\section{Competing interests}

The authors declare that they have no competing interests.

\section{Publisher's Note}

Springer Nature remains neutral with regard to jurisdictional claims in published maps and institutional affiliations.

\section{Author details}

${ }^{1}$ Department of Pulmonology, Leiden University Medical Center, V6-22, PO Box 9600, 2300 RC Leiden, the Netherlands. ${ }^{2}$ Department of Public Health and Primary Care, Leiden University Medical Center, Leiden, the Netherlands. ${ }^{3}$ Department of Clinical Epidemiology, Leiden University Medical Center, Leiden, the Netherlands. ${ }^{4}$ Department of Pulmonary Medicine, Ruhrlandklinik, West German Lung Center, University Hospital Essen, University

Duisburg-Essen, Essen, Germany.

Received: 18 July 2017 Accepted: 17 November 2017

Published online: 07 December 2017

\section{References}

1. Obesity and overweight. http://www.who.int/mediacentre/factsheets/fs311/ en/.

2. Bateman ED, Hurd SS, Barnes PJ, Bousquet J, Drazen JM, FitzGerald M, Gibson P, Ohta K, O'Byrne P, Pedersen SE, et al. Global strategy for asthma management and prevention: GINA executive summary. Eur Respir J. 2008;31(1):143-78.

3. Beuther DA, Sutherland ER. Overweight, obesity, and incident asthma: a meta-analysis of prospective epidemiologic studies. Am J Respir Crit Care Med. 2007:175(7):661-6.

4. Van Cleave J, Gortmaker SL, Perrin JM. Dynamics of obesity and chronic health conditions among children and youth. JAMA. 2010;303(7):623-30.

5. Ronmark E, Andersson C, Nystrom L, Forsberg B, Jarvholm B, Lundback B. Obesity increases the risk of incident asthma among adults. Eur Respir J. 2005;25(2):282-8.

6. Brazzale DJ, Pretto JJ, Schachter LM. Optimizing respiratory function assessments to elucidate the impact of obesity on respiratory health. Respirology. 2015;20(5):715-21.

7. Sutherland ER. Linking obesity and asthma. Ann N Y Acad Sci. 2014;1311:31-41.

8. Sutherland ER, Goleva E, King TS, Lehman E, Stevens AD, Jackson LP, Stream AR, Fahy JV, Leung DY, Asthma Clinical Research N. cluster analysis of obesity and asthma phenotypes. PLoS One. 2012;7(5):e36631.

9. Leiria LO, Martins MA, Saad MJ. Obesity and asthma: beyond $T(H) 2$ inflammation. Metab Clin Exp. 2015;64(2):172-81.

10. van Huisstede A, Rudolphus A, van Schadewijk A, Cabezas MC, Mannaerts GH, Taube C, Hiemstra PS, Braunstahl GJ. Bronchial and systemic inflammation in 
morbidly obese subjects with asthma: a biopsy study. Am J Respir Crit Care Med. 2014;190(8):951-4.

11. Westerhof GA, Korevaar DA, Amelink M, de Nijs SB, de Groot JC, Wang J, Weersink EJ, ten Brinke A, Bossuyt PM, Bel EH. Biomarkers to identify sputum eosinophilia in different adult asthma phenotypes. Eur Respir J. 2015:46(3):688-96.

12. Berg CM, Thelle DS, Rosengren A, Lissner L, Toren K, Olin AC. Decreased fraction of exhaled nitric oxide in obese subjects with asthma symptoms: data from the population study INTERGENE/ADONIX. Chest. 2011;139(5): 1109-16.

13. Sivapalan P, Diamant Z, Ulrik CS. Obesity and asthma: current knowledge and future needs. Curr Opin Pulm Med. 2015;21(1):80-5.

14. Pakhale S, Baron J, Dent R, Vandemheen K, Aaron SD. Effects of weight loss on airway responsiveness in obese adults with asthma: does weight loss lead to reversibility of asthma? Chest. 2015;147(6):1582-90.

15. van Huisstede A, Rudolphus A, Castro Cabezas M, Biter LU, van de Geijn GJ, Taube C, Hiemstra PS, Braunstahl GJ. Effect of bariatric surgery on asthma control, lung function and bronchial and systemic inflammation in morbidly obese subjects with asthma. Thorax. 2015;70(7):659-67.

16. Lucas AE, Smeenk FJ, Smeele IJ, van Schayck OP. Diagnostic accuracy of primary care asthma/COPD working hypotheses, a real life study. Respir Med. 2012;106(8):1158-63.

17. Luks VP, Vandemheen KL, Aaron SD. Confirmation of asthma in an era of overdiagnosis. Eur Respir J. 2010;36(2):255-60.

18. Scott S, Currie J, Albert P, Calverley P, Wilding JP. Risk of misdiagnosis, health-related quality of life, and BMI in patients who are overweight with doctor-diagnosed asthma. Chest. 2012;141(3):616-24.

19. van Huisstede A, Castro Cabezas M, van de Geijn GJ, Mannaerts GH, Njo TL, Taube C, Hiemstra PS, Braunstahl GJ. Underdiagnosis and overdiagnosis of asthma in the morbidly obese. Respir Med. 2013;107(9):1356-64.

20. Aaron SD, Vandemheen KL, Boulet LP, RA MI, Fitzgerald JM, Hernandez P, Lemiere C, Sharma S, Field SK, Alvarez GG, et al. Overdiagnosis of asthma in obese and nonobese adults. CMAJ. 2008;179(11):1121-31.

21. de Mutsert R, den Heijer M, Rabelink TJ, Smit JW, Romijn JA, Jukema JW, de Roos A, Cobbaert CM, Kloppenburg M, le Cessie S, et al. The Netherlands epidemiology of obesity (NEO) study: study design and data collection. Eur J Epidemiol. 2013;28(6):513-23.

22. ICPC. https://www.nhg.org/themas/artikelen/icpc.

23. ATC/DDD Index 2017. https://www.whocc.no/atc_ddd_index/.

24. de Hollander EL, Zwart L, de Vries SI, Wendel-Vos W. The SQUASH was a more valid tool than the OBiN for categorizing adults according to the Dutch physical activity and the combined guideline. J Clin Epidemiol. 2012;65(1):73-81.

25. Miller MR, Hankinson J, Brusasco V, Burgos F, Casaburi R, Coates A, Crapo R, Enright P, van der Grinten CP, Gustafsson P, et al. Standardisation of spirometry. Eur Respir J. 2005;26(2):319-38.

26. Thijs W, de Mutsert R, le Cessie S, Hiemstra PS, Rosendaal FR, Middeldorp S, Rabe KF. Reproducibility of exhaled nitric oxide measurements in overweight and obese adults. BMC Res Notes. 2014;7:775.

27. Dweik RA, Boggs PB, Erzurum SC, Irvin CG, Leigh MW, Lundberg JO, Olin AC, Plummer AL, Taylor DR, American Thoracic Society Committee on Interpretation of Exhaled Nitric Oxide Levels for Clinical A. An official ATS clinical practice guideline: interpretation of exhaled nitric oxide levels (FENO) for clinical applications. Am J Respir Crit Care Med. 2011;184(5):602-15.

28. Melo LC, Silva MA, Calles AC. Obesity and lung function: a systematic review. Einstein. 2014;12(1):120-5.

29. Thyagarajan B, Jacobs DR Jr, Apostol GG, Smith LJ, Jensen RL, Crapo RO, Barr RG, Lewis CE, Williams OD. Longitudinal association of body mass index with lung function: the CARDIA study. Respir Res. 2008;9:31.

30. Komakula S, Khatri S, Mermis J, Savill S, Haque S, Rojas M, Brown L, Teague GW, Holguin F. Body mass index is associated with reduced exhaled nitric oxide and higher exhaled 8-isoprostanes in asthmatics. Respir Res. 2007;8:32.

31. Barros R, Moreira A, Fonseca J, Moreira P, Fernandes L, de Oliveira JF, Delgado L, Castel-Branco MG. Obesity and airway inflammation in asthma. J Allergy Clin Immunol. 2006;117(6):1501-2.

32. Zammit $\mathrm{C}$, Liddicoat $\mathrm{H}$, Moonsie I, Makker H. Obesity and respiratory diseases. Int J Gen Med. 2010;3:335-43.

33. Schachter LM, Salome CM, Peat JK, Woolcock AJ. Obesity is a risk for asthma and wheeze but not airway hyperresponsiveness. Thorax. 2001;56(1):4-8.

34. Sin DD, Jones RL, Man SF. Obesity is a risk factor for dyspnea but not for airflow obstruction. Arch Intern Med. 2002;162(13):1477-81.
35. Carpio C, Villasante C, Galera R, Romero D, de Cos A, Hernanz A, Garcia-Rio F. Systemic inflammation and higher perception of dyspnea mimicking asthma in obese subjects. J Allergy Clin Immunol. 2016;137(3):718-26. e714

36. Durrington HJ, Farrow SN, Loudon AS, Ray DW. The circadian clock and asthma. Thorax. 2014;69(1):90-2.

37. Song WJ, Kim HJ, Shim JS, Won HK, Kang SY, Sohn KH, Kim BK, Jo EJ, Kim MH, Kim SH, et al. Diagnostic accuracy of fractional exhaled nitric oxide measurement in predicting cough-variant asthma and eosinophilic bronchitis in adults with chronic cough: a systematic review and meta-analysis. J Allergy Clin Immunol. 2017;140(3):701-9.

38. Karrasch S, Linde K, Rucker G, Sommer H, Karsch-Volk M, Kleijnen J, Jorres RA, Schneider A. Accuracy of FENO for diagnosing asthma: a systematic review. Thorax. 2016.

39. Umetsu DT. Mechanisms by which obesity impacts upon asthma. Thorax. 2017:72(2):174-7.

40. Salome CM, Munoz PA, Berend N, Thorpe CW, Schachter LM, King GG. Effect of obesity on breathlessness and airway responsiveness to methacholine in non-asthmatic subjects. Int J Obes. 2008;32(3):502-9.

41. Dombrowski SU, Knittle K, Avenell A, Araujo-Soares V, Sniehotta FF. Long term maintenance of weight loss with non-surgical interventions in obese adults: systematic review and meta-analyses of randomised controlled trials. BMJ. 2014;348:g2646.

42. Moore WC, Meyers DA, Wenzel SE, Teague WG, Li H, Li X, D'Agostino R Jr, Castro M, Curran-Everett D, Fitzpatrick AM, et al. Identification of asthma phenotypes using cluster analysis in the severe asthma research program. Am J Respir Crit Care Med. 2010;181(4):315-23.

\section{Submit your next manuscript to BioMed Central and we will help you at every step:}

- We accept pre-submission inquiries

- Our selector tool helps you to find the most relevant journal

- We provide round the clock customer support

- Convenient online submission

- Thorough peer review

- Inclusion in PubMed and all major indexing services

- Maximum visibility for your research

Submit your manuscript at www.biomedcentral.com/submit
Biomed Central 